\title{
The Local Antimagic On Disjoint Union of Some Family Graphs
}

\author{
Marsidi $^{1,2}$, Ika Hesti Agustin ${ }^{1,3^{*}}$ \\ CGANT Research Group, University of Jember, Indonesia ${ }^{1}$ \\ Mathematics Edu. Depart. IKIP PGRI Jember, Jember, Indonesia ${ }^{2}$, marsidiarin @ gmail.com² \\ Mathematics Depart. University of Jember, Jember, Indonesia ${ }^{3}$, ikahesti.fmipa@unej.ac.id ${ }^{3}$
}

doi: https://doi.org/10.15642/mantik.2019.5.2.69-75

\begin{abstract}
Abstrak: Graf $G$ pada penelitian ini adalah nontrivial, berhingga, terhubung, sederhana, dan tidak terarah. Misal $u, v$ adalah dua elemen di himpunan titik dan $q$ adalah kardinalitas himpunan sisi di graf $G$, fungsi bijektif dari himpunan sisi dipetakan ke bilangan asli $q$ disebut vertex local antimagic edge labeling jika untuk dua titik yang bertetangga $v_{1}$ dan $v_{2}$, bobot $v_{1}$ tidak sama dengan bobot $v_{2}$, dimana bobot $v$ (dinotasikan dengan $w(v)$ ) adalah jumlah label sisi yang terkait dengan $v$. Selanjutnya, setiap vertex local antimagic edge labeling menginduksi pewarnaan titik pada graf $G$ dimana $w(v)$ adalah warna pada titik $v$. Bilangan kromatik vertex local antimagic edge labeling $\chi_{l a}(G)$ adalah banyaknya warna minimum yang disebabkan oleh titik local antimagic pelabelan sisi pada graf $G$. Dalam artikel ini, kita membahas tentang bilangan kromatik vertex local antimagic edge labeling pada graf disjoint union dari keluarga graf seperti lintasan, lingkaran, bintang, dan friendship, dan menentukan batas bawah dari vertex local antimagic edge labeling. Nilai kromatik pada graf disjoint union pada penelitian ini mencapai batas bawah.
\end{abstract}

Kata kunci: pelabelan local antimagic, nilai kromatik local antimagic, graf disjoint union

\begin{abstract}
A graph $G$ in this paper is nontrivial, finite, connected, simple, and undirected. Graph $G$ consists of a vertex set and edge set. Let $u, v$ be two elements in vertex set, and $q$ is the cardinality of edge set in $G$, a bijective function from the edge set to the first $q$ natural number is called a vertex local antimagic edge labelling if for any two adjacent vertices $v_{1}$ and $v_{2}$, the weight of $v_{1}$ is not equal with the weight of $v_{2}$, where the weight of $v$ (denoted by $w(v)$ ) is the sum of labels of edges that are incident to $v$. Furthermore, any vertex local antimagic edge labelling induces a proper vertex colouring on where $w(v)$ is the colour on the vertex $v$. The vertex local antimagic chromatic number $\chi_{l a}(G)$ is the minimum number of colours taken over all colourings induced by vertex local antimagic edge labelling of $G$. In this paper, we discuss about the vertex local antimagic chromatic number on disjoint union of some family graphs, namely path, cycle, star, and friendship, and also determine the lower bound of vertex local antimagic chromatic number of disjoint union graphs. The chromatic numbers of disjoint union graph in this paper attend the lower bound.
\end{abstract}

Keywords: local antimagic labelling, local antimagic chromatic number, disjoint union graphs

How to cite: Marsidi and I. H. Agustin, "The local antimagic on disjoint union of some family graphs”, mantik, vol. 5, no. 2, pp. 69-75, October 2019. 


\section{Introduction}

Any mathematical object involving points and connection between them called a graph. A graph $G(V, E)$ consists of two sets $V$ and $E$. The elements of $V$ are called vertices, and the elements of $E$ called edges. The all graphs discussed in this paper are nontrivial, finite, connected, simple, and undirected [1] - [3]. Graph labelling is the assignment of labels to the graph elements such as edges or vertices, or both, from the graph. The concept of antimagic labelling of a graph was introduced by Hartsfield and Ringel [4]. Every component of the graph, such as vertex, edge, and face, has given the distinct label by a natural number.

Given a graph $G(V, E)$ and $\mathrm{q}$ is the number of edges in $\mathrm{G}$, a bijective function from the edges set to the first q natural number is called a vertex local antimagic edge labelling if for any two adjacent vertices $v_{1}$ and $v_{2}, w\left(v_{1}\right) \neq w\left(v_{2}\right)$, where $w(v)$ is the sum of labels of edges that are incident to $v$. Furthermore, any vertex local antimagic edge labelling induces a proper vertex colouring on where $w(v)$ is the colour on the vertex $v$. The minimum number of colours taken over all colourings induced by vertex local antimagic edge labelling of $G$ denoted by $\chi_{l a}(G)$.

If a graph $G$ has antimagic labelling, it is called antimagic. Since been introduced by Hartsfield and Ringel [4], the topic has attracted a lot of attention, for details, see Gallian [11]. One of well-known remark and theorem related to this is the following.

Remark 1.1. For any graph $G, \chi_{l a}(G) \geq \chi(G)$ and the difference $\chi_{l a}(G)-$ $\chi(G)$ can be arbitrarily large [4].

Theorem 1.1. For any tree $T$ with l leaves, $\chi_{l a}(T) \geq l+1$ [5].

Arumugam et al. [5] give a lower bound and upper bound of local antimagic vertex colouring of $K_{1}+H$ and also give the exact value of local antimagic vertex colouring. Agustin et al. [6] studied the local edge antimagic colouring of graphs. The other results about local antimagic of graphs can be seen in [6] -[10].

Thus, in this paper, we have found the chromatic number of vertex local antimagic chromatic number on disjoint union of some family graphs, namely path, cycle, star, and friendship. Before we present our results, we define a definition of disjoint union graph that we discuss in this paper. For any graph $G$, the graph $\bigcup_{i=m} G$ denotes the disjoint union of $m$ copies of graph $G$.

\section{Main Result}

In this section, we present our results by showing the vertex local antimagicchromatic number on disjoint union of some family graphs, namely path, cycle, star, and friendship in the following theorems. We also present the remark and theorem about the lower bound of the disjoint union of graphs. $\chi_{l a}(G)$.

Remark 2.1. For any disjoint union graph $G$, we have $\chi_{\text {la }}\left(\cup_{i=m} G\right) \geq$

Theorem 2.1. For any tree $T$ with kpendant vertices, $\chi_{l a}\left(\bigcup_{i=m} T\right) \geq k+1$ 
Proof. Let $g$ be any local antimagic labelling of disjoint union of $T$, then the colouring induced by $g$. The colour of a pendant vertex $v$ is the label on edge that is incident with $v$. Thus, all the pendant vertices receive distinct colours. Furthermore, for any non-pendant vertex incident with an edge $e_{1}$ with $f\left(e_{1}\right)=$ $m$, the colour assigned to $w$ is larger than $m$. Since the number of colours in the colouring induced by $g$ is at least $k+1, \chi_{l a}\left(\bigcup_{i=m} T\right) \geq k+1$.

Theorem 2.2. For the path $P_{n}$ with $n \geq 3$, then we have $\chi_{l a}\left(\cup_{j=m} P_{n}\right)=$ $2 m+1$.

Proof. The $\bigcup_{j=m} P_{n}$ is the disjoint union of path graph. The Vertex set is $V\left(\bigcup_{j=m} P_{n}\right)=\left\{v_{1}^{1}, v_{2}^{1}, \ldots, v_{i}^{j}, \ldots, v_{n-1}^{m}, v_{n}^{m} ; i \in\{1,2,3, \ldots, n\}, j \in\{1,2,3, \ldots, m\}\right\}$ and the edge set $E\left(\bigcup_{j=m} P_{n}\right)=\left\{v_{1}^{1} v_{2}^{1}, v_{2}^{1} v_{3}^{1} \ldots, v_{i}^{j} v_{i+1}^{j}, \ldots, v_{n-2}^{m} v_{n-1}^{m}, v_{n-1}^{m} v_{n}^{m} ; i \in\right.$ $\{1,2,3, \ldots, n-1\}, j \in\{1,2,3, \ldots, m\}\}$. Hence $\left|V\left(\mathrm{U}_{j=m} P_{n}\right)\right|=$ $m n,\left|E\left(\cup_{j=m} P_{n}\right)\right|=m(n-1)$. Because graph $\bigcup_{j=m} P_{n}$ have $2 m$ leaves, based on Theorem 2.1, we have $\chi_{l a}\left(\bigcup_{i=m} T\right) \geq k+1$, so the color needed for $\bigcup_{j=m} P_{n}$ is $2 m+1$. Thus, we have $\chi_{l a}\left(U_{j=m} P_{n}\right) \geq 2 m+1$.

Furthermore, we will prove that the upper bound is $2 m+1$, denoted by $\chi_{l a}\left(\bigcup_{j=m} P_{n}\right) \leq 2 m+1$. We define the labelling on the edges of $P_{n}$ by the following functions.

$$
f\left(v_{i}^{j} v_{i+1}^{j}\right)=\left\{\begin{aligned}
\frac{1}{2}(i+j(n-1)-n+1, & i \in\{2,4,6, \ldots, n-1\} ; \\
m(n-1)+\left(\frac{n-i}{2}\right)-j\left(\frac{n-1}{2}\right), & i \in\{1,3,5, \ldots, n-2\} ; \\
& j \in\{1,2,3, \ldots, m\} \text { for } n \text { odd } \\
\left(\frac{i}{2}-1\right) m+j, & i \in\{2,4,6, \ldots, n-2\} ; \\
& j \in\{1,2,3, \ldots, m\} \text { for } n \text { even } \\
m n-m\left(\frac{i+1}{2}\right)-j+1, & i \in\{1,3,5, \ldots, n-1\} ; \\
& j \in\{1,2,3, \ldots, m\} \text { for } n \text { even }
\end{aligned}\right.
$$

Base on the function $f$, we determine the set of vertex weight on pendant vertices as the following.

$$
\begin{aligned}
W_{1} & =\left\{f ( v _ { 1 } ^ { j } ; j \in \{ 1 , 2 , 3 , \ldots , m \} \} \cup \left\{f\left(v_{n}^{j} ; j \in\{1,2,3, \ldots, m\}\right\}\right.\right. \\
& =\left\{m(n-1), m(n-1)-\left(\frac{n-1}{2}\right), \ldots,(m+1)\left(\frac{n-1}{2}\right)\right\} \cup\left\{\frac{n-1}{2}, n-1, \ldots, \frac{m(n-1)}{2}\right\}
\end{aligned}
$$

The vertex weights on the two degrees vertices are

$$
\begin{gathered}
W_{2}=m(n-1)+1 \\
W_{3}=m(n-1)
\end{gathered}
$$

Hence from the above, it easy to see that the different vertex weights are $2 m+1$, so $\quad \chi_{l a}\left(\bigcup_{j=m} P_{n}\right) \leq 2 m+1$. Therefore $\chi_{l a}\left(\bigcup_{j=m} P_{n}\right) \leq 2 m+1 \quad$ and $\chi_{l a}\left(\mathrm{U}_{j=m} P_{n}\right) \geq 2 m+1$. It concludes that $\chi_{l a}\left(\mathrm{U}_{j=m} P_{n}\right)=2 m+1$.

The illustration of local antimagic labelling of $\bigcup_{j=m} P_{n}$ can be seen in Figure 1 . 

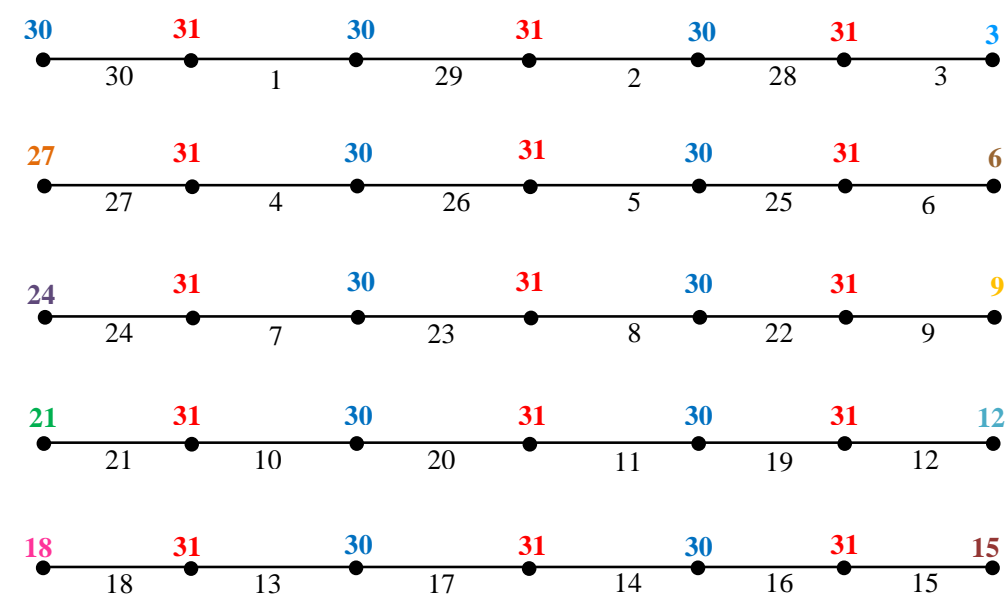

Figure 1. Illustration of local antimagic labelling of $\mathrm{U}_{m=5} P_{7}$

Theorem 2.3. For the cycle $C_{n}$ with $n \geq$ three and $n$ is even integer, then we have $\chi_{l a}\left(\mathrm{U}_{j=m} C_{n}\right)=3$.

Proof. The $\cup_{j=m} C_{n}$ is the disjoint union of cycle graph.The vertex set $V\left(\bigcup_{j=m} C_{n}\right)=\left\{v_{1}^{1}, v_{2}^{1}, \ldots, v_{i}^{j}, \ldots, v_{n-1}^{m}, v_{n}^{m} ; i \in\{1,2,3, \ldots, n\}, j \in\{1,2,3, \ldots, m\}\right.$ and the edge set $E\left(\bigcup_{j=m} P_{n}\right)=\left\{e_{1}^{1}, e_{2}^{1}, e_{3}^{1}, \ldots, e_{n}^{1}, \ldots, e_{i}^{j}, \ldots, e_{n-1}^{m}, e_{n}^{m}\right.$, where $e_{1}^{1},=$ $\left.v_{1}^{1} v_{2}^{1}, e_{2}^{1}=v_{2}^{1} v_{3}^{1}, \ldots, e_{n}^{1}=v_{n}^{1} v_{1}^{1} ; i \in\{1,2,3, \ldots, n\}, j \in\{1,2,3, \ldots, m\}\right\}$. Hence $\left|V\left(\bigcup_{j=m} P_{n}\right)\right|=m n,\left|E\left(\cup_{j=m} P_{n}\right)\right|=m n$. We will prove that $\chi_{l a}\left(\cup_{j=m} C_{n}\right) \geq$ 3. Based on Arumugam theorem [4], the local antimagic chromatic number of cycle graph is $\chi_{l a}\left(C_{n}\right)=3$. Furthermore, based on Remark 2.1 we have $\chi_{l a}\left(\cup_{i=m} C_{n}\right) \geq \chi_{l a}\left(C_{n}\right)$ so we can see that $\chi_{l a}\left(\cup_{j=m} C_{n}\right) \geq 3$.

Furthermore, we will prove that the upper bound is 3 , denoted $\chi_{l a}\left(U_{j=m} C_{n}\right) \leq 3$, by defining the labelling as follow.

$$
g\left(e_{i}^{j}\right)=\left\{\begin{array}{l}
\frac{1}{2}(i+1)+\frac{1}{2}(j-1), \quad \text { for } i \in\{1,3,5, \ldots, n-1\}, j \in\{1,2,3, \ldots, m\} \\
n m+1-\frac{i}{2}-\frac{n}{2}(j-1), \quad \text { for } i \in\{2,4,6, \ldots, n\}, j \in\{1,2,3, \ldots, m\}
\end{array}\right.
$$

Then we have the vertex weights as follow:

$$
W\left(e_{i}^{j}\right)=\left\{\begin{array}{c}
n m+1, \text { for } i \in\{1,3,5, \ldots, n-1\}, j \in\{1,2,3, \ldots, m\} \\
n m+2, \text { for } i=1,3,5, \ldots, n-1, j \in\{1,2,3, \ldots, m\} \\
n m+2-\frac{n}{2}, \text { for } i=n, j \in\{1,2,3, \ldots, m\}
\end{array}\right.
$$

Hence from the function above, it easy to see that the vertex weight $W\left(e_{i}^{j}\right)=$ $\left\{n m+1, n m+2, n m+2-\frac{n}{2}\right\}$ contains three elements which induce a proper vertex colouring of $\bigcup_{j=m} C_{n}$. Thus, it gives $\chi_{l a}\left(\cup_{j=m} C_{n}\right) \leq 3$. It concludes that $\chi_{l a}\left(\mathrm{U}_{j=m} C_{n}\right)=3$. 
Theorem 2.4. For the star $S_{n}$ with $n \geq 3$, then we have $\chi_{l a}\left(\cup_{j=m} S_{n}\right)=$ $n m+1, m \neq$ even integer when $n$ is an odd integer.

Proof. The $\mathrm{U}_{j=m} S_{n}$ is the disjoint union of star graph. The vertex set $V\left(\mathrm{U}_{j=m} S_{n}\right)=\left\{A, v_{1}^{1}, v_{2}^{1}, \ldots, v_{i}^{j}, \ldots, v_{n-1}^{m}, v_{n}^{m} ; i \in\{1,2,3, \ldots, n\}, j \in\{1,2,3, \ldots, m\}\right\}$ and the edge set $E\left(\bigcup_{j=m} P_{n}\right)=$ $\left\{A v_{1}^{1}, A v_{2}^{1}, A v_{3}^{1} \ldots, A v_{i}^{j}, \ldots, A v_{1}^{m}, A v_{2}^{m}, \ldots, A v_{n-1}^{m}, A v_{n}^{m} ; i \in\{1,2,3, \ldots, n\}, j \in\right.$ $\{1,2,3, \ldots, m\}\}$. Hence $\left|V\left(\cup_{j=m} S_{n}\right)\right|=m n+m,\left|E\left(\cup_{j=m} S_{n}\right)\right|=m n$. We will prove that $\chi_{l a}\left(\bigcup_{j=m} S_{n}\right) \geq n m+1$. Graph $\bigcup_{j=m} S_{n}$ havenm leaves, based on Theorem 2.1, we have $\chi_{l a}\left(\cup_{i=m} T\right) \geq k+1$ so the color needed for $\bigcup_{j=m} S_{n}$ is $\chi_{l a}\left(\cup_{j=m} S_{n}\right) \geq n m+1$.

Furthermore, we will prove that the upper bound is $\chi_{l a}\left(\cup_{j=m} S_{n}\right) \leq n m+1$, we define the labelling into two cases by the following.

Case 1. For $n$ even

$$
h\left(A x_{i}^{j}\right)=\left\{\begin{array}{c}
m(i-1)+j ; i \in\{1,3,5, \ldots, n-1\}, j \in\{1,2,3, \ldots, m\} \\
m i-j+1 ; i \in\{2,4,6, \ldots, n\}, j \in\{1,2,3, \ldots, m\}
\end{array}\right.
$$

Case 2. For $n$ odd

$$
h\left(A x_{i}^{j}\right)=\left\{\begin{array}{c}
\frac{j+1}{2} ; i=1, j \in\{1,3,5, \ldots, m\} \\
\frac{m+j+1}{2} ; i=1, j \in\{2,4,6, \ldots, m-1\} \\
\frac{j}{2}+m ; i=2, j \in\{2,4,6, \ldots, m-1\} \\
\frac{3 m+j}{2} ; i=2, j \in\{1,3,5, \ldots, m\} \\
3 m+1-j ; j \in\{1,2,3, \ldots, m\} \\
m i-j+1 ; i \in\{4,6,8, \ldots, n-1\} ; j \in\{1,2,3, \ldots, m\} \\
m(i-3)-j+1 ; i \in\{5,7,9, \ldots, n\} ; j \in\{1,2,3, \ldots, m\}
\end{array}\right.
$$

Based on the labelling above, the weight on each pendant vertex is the label of the edge which incident with pendant vertex. Therefore, the number of vertex weight on the disjoint union of star graph is $\mathrm{nm}$. The weight of each centre vertex is as follow.

$$
W(A)=\frac{n}{2}(n m+1)
$$

Because the number of pendant vertex is $n m$, the number of different vertex weight on the disjoint union of star graph is $n m+1$, so $\chi_{l a}\left(U_{j=m} S_{n}\right) \leq n m+$ 1.Therefore $\quad \chi_{l a}\left(\cup_{j=m} S_{n}\right) \leq n m+1 \quad$ and $\quad \chi_{l a}\left(U_{j=m} S_{n}\right) \geq n m+1$, it concludes $\chi_{l a}\left(U_{j=m} S_{n}\right)=n m+1$

Theorem 2.5. For the friendship $\mathcal{F}_{n}$ with $n \geq$ three and $n$ is even integer, then we have $\chi_{l a}\left(\bigcup_{j=m} \mathcal{F}_{n}\right)=3$. 
Proof. The $\bigcup_{j=m} \mathcal{F}_{n}$ is the disjoint union of friendship graph. The vertex set $V\left(\bigcup_{j=m} \mathcal{F}_{n}\right)=\{A\} \cup\left\{u_{1}^{1}, u_{2}^{1}, \ldots, u_{i}^{j}, \ldots, u_{n-1}^{m}, u_{n}^{m} ; i \in\{1,2,3, \ldots, n\} ; j \in\right.$ $\{1,2,3, \ldots, m\}\} \cup\left\{v_{1}^{1}, v_{2}^{1}, \ldots, v_{i}^{j}, \ldots, v_{n-1}^{m}, v_{n}^{m} ; i \in\{1,2,3, \ldots, n\} ; j \in\right.$ $\{1,2,3, \ldots, m\}\}$ and the edge set $E\left(\cup_{j=m} \mathcal{F}_{n}\right)=$ $\left\{A u_{1}^{1}, A u_{2}^{1}, A u_{3}^{1} \ldots, A u_{i}^{j}, \ldots, A u_{1}^{m}, A u_{2}^{m}, \ldots, A u_{n-1}^{m}, A u_{n}^{m} ; i \in\{1,2,3, \ldots, n\} ; j \in\right.$ $\{1,2,3, \ldots, m\}\} \cup\left\{A v_{1}^{1}, A v_{2}^{1}, A v_{3}^{1} \ldots, A v_{i}^{j}, \ldots, A v_{1}^{m}, A v_{2}^{m}, \ldots, A v_{n-1}^{m}, A v_{n}^{m} ; i \in\right.$ $\{1,2,3, \ldots, n\} ; j \in\{1,2,3, \ldots, m\}\} \cup$ $\left\{u_{1}^{1} v_{1}^{1}, u_{2}^{1} v_{2}^{1}, \ldots, u_{i}^{j} v_{i}^{j}, \ldots, u_{n-1}^{m} v_{n-1}^{m}, u_{n}^{m} v_{n}^{m} ;\right\}$. Hence $\left|V\left(\bigcup_{j=m} \mathcal{F}_{n}\right)\right|=2 m n+m$, $\left|E\left(\cup_{j=m} \mathcal{F}_{n}\right)\right|=3 m n$. We will prove that $\chi_{l a}\left(\cup_{j=m} \mathcal{F}_{n}\right) \geq 3$. Based on Arumugam theorem [4], the local antimagic chromatic number of friendship graph is $\chi_{\text {la }}\left(\mathcal{F}_{n}\right)=3$. Furthermore, based on Remark 2.1 we have $\chi_{\text {la }}\left(\cup_{i=m} \mathcal{F}_{n}\right) \geq$ $\chi_{l a}\left(\mathcal{F}_{n}\right)$ so we can see that $\chi_{l a}\left(\bigcup_{j=m} \mathcal{F}_{n}\right) \geq 3$.

Furthermore, we will prove that the upper bound is 3, denoted $\chi_{l a}\left(\cup_{j=m} \mathcal{F}_{n}\right) \leq 3$, we define the labeling by the following.

$$
\begin{gathered}
f\left(A u_{i}^{j}\right)=\left\{\begin{array}{c}
m(i-1)+j ; i \in\{1,3,5, \ldots, n-1\} ; j \in\{1,2,3, \ldots, m\} \\
m i-j+1 ; i \in\{2,4,6, \ldots, n\} ; j \in\{1,2,3, \ldots, m\}
\end{array}\right. \\
f\left(A v_{i}^{j}\right)=\left\{\begin{array}{c}
m(i-1)+j+2 m n ; i \in\{1,3,5, \ldots, n-1\} ; j \in\{1,2,3, \ldots, m\} \\
m i-j+1+2 m n ; i \in\{2,4,6, \ldots, n\} ; j \in\{1,2,3, \ldots, m\}
\end{array}\right. \\
f\left(u_{i}^{j} v_{i}^{j}\right)=\left\{\begin{array}{c}
2 m n+1-m(i-1)-j ; i \in\{1,3,5, \ldots, n-1\} ; j \in\{1,2,3, \ldots, m\} \\
2 m n-m i+j ; i \in\{2,4,6, \ldots, n\} ; j \in\{1,2,3, \ldots, m\}
\end{array}\right.
\end{gathered}
$$

Based on the labeling above, we have the vertex weights as follows:

$$
\begin{gathered}
W_{1}(A)=3 m n^{2}+n \\
W_{2}\left(u_{i}^{j}\right)=2 m n+1, \text { for } i \in\{1,2,3, \ldots, n-1\} ; j \in\{1,2,3, \ldots, m\} \\
W_{3}\left(v_{i}^{j}\right)=4 m n+1, \text { for } i \in\{1,2,3, \ldots, n-1\} ; j \in\{1,2,3, \ldots, m\}
\end{gathered}
$$

Hence from the above, it easy to see that the vertex weight $W=$ $\left\{3 m n^{2}+n, 2 m n+1,4 m n+1\right\}$ contains 3 element which induces a proper vertex coloring of $\bigcup_{j=m} C_{n}$, so $\chi_{l a}\left(U_{j=m} \mathcal{F}_{n}\right) \leq 3$. Therefore $\chi_{l a}\left(U_{j=m} \mathcal{F}_{n}\right) \leq 3$ and $\chi_{l a}\left(\mathrm{U}_{j=m} \mathcal{F}_{n}\right) \geq 3$, it concludes $\chi_{l a}\left(\mathrm{U}_{j=m} \mathcal{F}_{n}\right)=3$.

\section{Concluding Remarks}

All results in this paper are the vertex local antimagic chromatic number of disjoint union of the path, cycle, star, and friendship graph. The vertex local antimagic chromatic number of all graphs in this paper has attended the lower bound.

Open Problem. Find the vertex local antimagic chromatic number on disjoint union of cycle and friendship when the number of their vertices is odd, disjoint union of a star when the number of copies is even where the number of vertice sis odd, and also find the vertex local antimagic of disjoint union of another graph. 


\section{Acknowledgement}

We gratefully acknowledge the support from CGANT University of Jember and IKIP PGRI Jember of the year 2019.

\section{References}

[1] J. L. Gross, J. Yellen, and P. Zhang, Handbook of graph Theory Second Edition. CRC Press Taylor and Francis Group, 2014

[2] G. Chartrand, L. Lesniak, and P. Zhang, Graphs \& Digraphs 6th Edition. CRC Press: Taylor \& Francis Group, 2016

[3] D. Zaenab, D. Adyanti, A. Fanani, and N. Ulinnuha, "Aplikasi Graph Coloring pada Penjadwalan Perkuliahan di Fakultas Sains dan Teknologi UIN Sunan Ampel Surabaya", mantik, vol. 2, no. 1, pp. 30-39, October 2016.

[4] J. L. Gross, J. Yellen, and P. Zhang, Handbook of Graph Theory Second Edition. CRC Press Taylor and Francis Group, 2014

[5] S. Arumugam S, K. Premalatha, M. Baca and A. Semanicova-Fenovcikova, "local antimagic vertex colouring of a graph", Graphs and Combinatorics Volume 33, Issue 2, pp. 275-285, 2017

[6] I. H. Agustin, Dafik, M. Hasan, R. Alfarisi R, and R. M. Prihandini, "local edge antimagic colouring of graphs". in Far East Journal of Mathematical Sciences, 102(9):1925-1941, 2017

[7] I. H. Agustin, S. Dafik, R. Alfarisi, E.Y. Kurniawati, "The construction of super local edge antimagic total coloring by using an EAVL Technique accepted", 2017

[8] I. H. Agustin, S. Dafik, E. R. Ermita, R. Alfarisi, "On the total local edge super antimagicness of special graph and graph with pendant edge accepted, 2017

[9] E. Y. Kurniawati, I. H. Agustin, Dafik, and R. Alfarisi. Super local edge antimagic total colouring of $\{\mathrm{P}\}_{-}\{\mathrm{n}\} \mid$ vartriangleright $\mathrm{H}$, Journal of Physics: Conference Series, Volume 1008, Issue 1, 2018

[10] E. Y. Kurniawati, I. H. Agustin, Dafik, R. Alfarisi, and Marsidi, "On the local edge antimagic total chromatic number of amalgamation of graphs", AIP Conference Proceedings, 2018

[11] Yung-Ling Lai and G. J. Chang, "On the profile of the corona of two graphs, Information Processing Letters, Vol. 89, Issue 6, pp. 287-292, 2004 